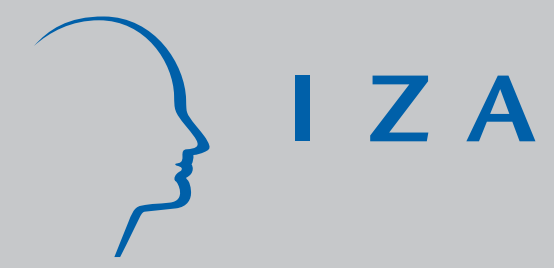

IZA DP No. 3849

The Effect of Integration Policies on the Time until Regular Employment of Newly Arrived Immigrants: Evidence from Denmark

J ens Clausen

Eskil Heinesen

Hans Hummelgaard

Leif Husted

Michael Rosholm

November 2008 


\title{
The Effect of Integration Policies on the Time until Regular Employment of Newly Arrived Immigrants: Evidence from Denmark
}

\author{
Jens Clausen \\ AKF, Danish Institute of Governmental Research \\ Eskil Heinesen \\ AKF, Danish Institute of Governmental Research \\ Hans Hummelgaard \\ AKF, Danish Institute of Governmental Research \\ Leif Husted \\ AKF, Danish Institute of Governmental Research
}

Michael Rosholm

Aarhus School of Business and IZA

Discussion Paper No. 3849

November 2008

\author{
IZA \\ P.O. Box 7240 \\ 53072 Bonn \\ Germany \\ Phone: +49-228-3894-0 \\ Fax: +49-228-3894-180 \\ E-mail: iza@iza.org
}

Any opinions expressed here are those of the author(s) and not those of IZA. Research published in this series may include views on policy, but the institute itself takes no institutional policy positions.

The Institute for the Study of Labor (IZA) in Bonn is a local and virtual international research center and a place of communication between science, politics and business. IZA is an independent nonprofit organization supported by Deutsche Post World Net. The center is associated with the University of Bonn and offers a stimulating research environment through its international network, workshops and conferences, data service, project support, research visits and doctoral program. IZA engages in (i) original and internationally competitive research in all fields of labor economics, (ii) development of policy concepts, and (iii) dissemination of research results and concepts to the interested public.

IZA Discussion Papers often represent preliminary work and are circulated to encourage discussion. Citation of such a paper should account for its provisional character. A revised version may be available directly from the author. 
IZA Discussion Paper No. 3849

November 2008

\begin{abstract}
The Effect of Integration Policies on the Time until Regular Employment of Newly Arrived Immigrants: Evidence from Denmark ${ }^{*}$

We analyse the effect of active labour-market programmes on the hazard rate into regular employment for newly arrived immigrants using the timing-of-events duration model. We take account of language course participation and progression in destination country language skills. We use rich administrative data from Denmark. We find substantial lock-in effects of participation in active labour-market programmes. Post programme effects on the hazard rate to regular employment are significantly positive for wage subsidy programmes, but not for other types of programmes. For language course participants, improvement in language proficiency has significant and substantial positive effects on the hazard rate to employment.
\end{abstract}

JEL Classification: J64, J24, J68, J61, C41

Keywords: programme evaluation, duration analysis, language skills

Corresponding author:

Eskil Heinesen

Danish Institute of Governmental Research

Nyropsgade 37

DK-1602 Copenhagen $V$

Denmark

E-mail: esh@akf.dk 


\section{Introduction}

Immigration of people from non-western countries to Europe has increased over the last four decades. In most European countries immigrants have much lower labour-market participation rates than natives (OECD, 2005). More successful labour-market integration is important for aggregate labour supply, economic growth and public finances, and specifically, it may contribute to alleviating the problems of non-sustainable public finances in the long term caused by aging European populations. In the Scandinavian welfare states, however, the low labour-market participation rates of non-western immigrants currently represent a financial burden in terms of net public expenditure (see Wadensjö, 2001; Pedersen, 2005). As a consequence of these issues, successful labour-market integration of newly arrived immigrants has become a major policy issue in most European countries. The Scandinavian welfare states have had quite a success recently in bringing down equilibrium unemployment rates while maintaining high participation rates, which has in part been attributed to the fairly flexible institutions and policies surrounding the labour market; the so-called Flexicurity model. However, this success apparently does not extend into the area of integration of nonwestern immigrants, where policies so far have failed miserably.

The contribution of this paper is to shed additional light on this issue by analysing the effect of new Danish integration policies specifically designed for facilitating the labour-market integration of newly arrived immigrants. These policies, introduced systematically on a large scale in 1999, consist of destination country language training and several elements of active labour-market programmes (ALMPs). We investigate the effects of these policies on the rate at which newly arrived immigrants find regular employment. We focus on ALMP effects taking account of language skills and participation in language training. We use rich administrative data from Denmark on transitions between labour-market states and participation in labour-market programmes and attendance of Danish language 
training courses. For language training participants we are able to measure initial proficiency in Danish and progression in proficiency. Taking into account host country language proficiency may be very important when estimating effects of ALMPs for immigrants since language skills often have large effects on labour-market integration; see, e.g., Chiswick and Miller (1995, 2003). We use the timing-of-events duration model of Abbring and van den Berg (2003), and argue that the identifying assumption of no anticipation effects is reasonable in this case of newly arrived immigrants. We calculate average marginal effects of ALMPs on (restricted) mean duration until regular employment for different ALMPs. To our knowledge, this paper is the first study of effects of ALMPs specifically applied to speed up the integration process of immigrants.

We find significant and substantial lock-in effects of participation in labourmarket programmes on the hazard rate to regular employment. Programme effects on the hazard rate to employment are significantly positive for private sector wage subsidies, but not for other ALMPs. Improvement in language skills significantly increases the hazard rate to employment for participants in language courses.

The paper is organised as follows. Section 2 describes the institutional settings surrounding the integration process for newly arrived immigrants, and Section 3 develops the econometric model. Section 4 describes the data used in the empirical analysis, and Section 5 presents main results. Section 6 concludes and discusses policy implications of our results.

\section{Institutional setting}

From 1999 onwards Danish municipalities have had the full responsibility for active policies aimed at integrating new immigrants into the labour market. The group of immigrants for which the municipalities have these obligations are persons who 1) have received their residence permit after January $\left.1^{\text {st }} 1999,2\right)$ were $16-64$ years of age when they received their 
residence permit, 3) are from non-EU and non-Nordic countries, and 4) are refugees or family reunified. The overall framework for Danish integration policy is determined by national law, but the 271 municipalities have significant discretion regarding administration of the law and specific implementation of the policies.

It is the responsibility of the municipalities to offer a three-year integration programme that has two main elements. Firstly, municipalities are responsible for offering immigrants Danish language training. Secondly, while immigrants who have gained a residence permit, and who cannot support themselves or be supported by relatives, are eligible for social security benefits, another objective of the local authorities is to make this group self-supporting through employment, an objective which is to be achieved through the use of ALMPs. Thus, all immigrants meeting the four criteria listed above are offered Danish language courses, while ALMPs are primarily offered to immigrants receiving social security benefits.

\subsection{Language courses}

There are three different tracks of Danish language courses. Courses on the first track are offered to illiterates and immigrants who have not learned the Roman alphabet, and the main purpose is to enable the immigrant to attend courses on the second track. Courses on the second and third tracks are offered to immigrants having a low and a higher level of schooling, respectively, and the purpose is that immigrants obtain language skills normally required in the labour market. The course load corresponds to 1.2 years of full-time education, but the courses are also offered as part-time courses during a three-year period in order to enable immigrants to work or participate in labour-market programmes simultaneously. There are

three levels of teaching on track 1, two levels on track 2, and four levels on track 3, see Figure 1. At each level teaching is offered at three sublevels ('start', 'middle' and 'end'). The 
different levels (and sublevels) correspond to different language skills. For instance, immigrants starting at level 1 on tracks 2 and 3, respectively, are assumed to have approximately the same Danish language skills at the outset, but immigrants on track 3 are assumed to have better prerequisites for learning Danish because of their higher educational level, and they are therefore expected to progress faster to a higher level of proficiency in Danish.

\section{[FIGURE 1 ABOUT HERE]}

Apart from information on track assignment, we use two variables as indicators of language skills. First, a variable for initial language skills, initial, taking values between -2 and 3 2/3 with steps of 1/3; see Figure 1. For instance, for a person assigned to track 1, level 1, sublevel 'start' the value of this variable is -2 , whereas it is 0 for a person assigned to track 2 (or 3), level 1, sublevel 'start'. The second variable measures progression in language skills and is time-varying. Progression is observed when an immigrant begins taking courses at a higher level or sublevel (we do not observe completion of courses). For instance, for a person having started on tracks 2 or 3, level 1, sublevel 'start', this variable, progression, has the value $1 / 3$ when the person attends courses at level 1 , sublevel 'middle', and the value 1 when the person attends courses at level 2, sublevel 'start'. The scale used for these two variables is based on the administrative division of the courses at each track into levels and sublevels, but the scale also roughly reflects the expected number of lessons needed to progress from one sublevel to the next within each track. ${ }^{1}$ 


\subsection{Active labour-market programmes}

There are six different types of active labour-market programmes offered to immigrants: Employment with a wage subsidy in private sector firms; direct employment programmes taking place in the public sector; education and training; mixed special programmes; counselling and upgrading; and special employment programmes in private sector firms. Mixed special programmes are designed to improve personal and vocational skills through combinations of different measures. Counselling and upgrading programmes are primarily socalled introduction programmes and counselling regarding employment and education options, but they may also include voluntary unpaid work, adult education and supplementary training. Special employment programmes are subsidised private sector employment, primarily for vulnerable groups of immigrants.

\section{Econometric model}

We use the timing-of-events duration model of Abbring and van den Berg (2003) which has been used to evaluate ALMPs in several previous studies; see, e.g., Richardson and van den Berg (2001), van den Berg et al. (2004), Abbring et al. (2005), Crépon et al. (2005), Lalive et al. (2005, 2008), and Rosholm and Svarer (2008). We model the duration from date of residence permit to regular employment simultaneously with the duration from time of residence permit until entry into active labour-market programmes. The model takes account of non-random selection into these programmes with respect to observable and unobservable covariates. Assuming mixed proportional hazard (MPH) rates and no anticipation effects, the treatment effects (i.e. the effects of participating in labour-market programmes) are nonparametrically identified; see Abbring and van den Berg (2003). The no-anticipation assumption requires that a treatment starting at time $t$ should not affect the outcome state (employment or non-employment) before time $t$. This may be a reasonable assumption in the 
present application since typically immigrants are not able to predict neither time of treatment nor the specific programme to which they may be assigned. Given this assumption, no exclusion restrictions are needed. The intuition behind the identification strategy intrinsic to the timing-of-events model is that there is some random variation in the duration until treatment. This enables a separation between the treatment effect and unobserved heterogeneity, which is assumed time-invariant.

The baseline hazard rate is modelled flexibly by a piecewise constant function, and time-varying variables are used for modelling lock-in and programme effects of ALMPs, and to take account of language course participation and the changing level of language skills.

As stated above, we model explicitly the selection into labour-market programmes. We do not model the selection into language courses. Apart from the need to simplify the model, this is due to the fact that the track of language courses to which immigrants are assigned is largely determined by their educational level which is predetermined. Thus, the initial assignment to language tracks is a proxy for the educational level of immigrants at the time of arrival, hence, to model the language training track would not make much sense.

However, we have no information on language skills for immigrants who do not participate in language training, and some of the non-participants may not need to participate, for instance because they speak Danish already or because they very quickly get a job which does not require Danish language skills. This implies that the decision to participate in language training or not may be an endogenous variable. Hence, although we do estimate lock-in and programme effects of language courses using time-varying explanatory variables, including indicators for progression of language skills, a process which may also be endogenous, these effects may not be interpreted as causal. The variables related to language courses are included in the vector $x(t)$ in the model described below. 
Normalising the time at which immigrants obtain their residence permit to zero, the non-negative stochastic variables $T_{u}$ and $T_{p}$ measure duration until employment and duration until programme participation, respectively. By construction, $T_{p} \leq T_{u}$. If $T_{p}<T_{u}$ the immigrant participates in a programme, and if $T_{p}=T_{u}$ he does not (the duration until participation is right censored).

Let $x(t)$ be a vector of observed time-varying variables, and let $v_{u}$ and $v_{p}=\left(v_{p 1}, \ldots, v_{p J}\right)$ denote unobserved variables affecting the hazard rates to employment and to participation in each of the $J$ programmes, respectively. The hazard rate to participation in programme $j$ is

$$
\theta_{p j}\left(t_{p} \mid x\left(t_{p}\right), v_{p j}\right)=\lambda_{p j}\left(t_{p}\right) \exp \left(x\left(t_{p}\right) \beta_{p j}+v_{p j}\right)
$$

where $\lambda_{p j}\left(t_{p}\right)$ are piecewise constant baseline hazard rates,

$$
\lambda_{p j}\left(t_{p}\right)=\sum_{m=1}^{M} \gamma_{p j m} 1\left\{h_{m-1} \leq t_{p}<h_{m}\right\}, \quad h_{0}=0, h_{M}=\infty, h_{0}<\ldots<h_{M}
$$

In this application the intervals are quarters (from the date of residence permit), i.e. $h_{m}=13 m$ since the time unit is weeks. The hazard rate to programme participation is the sum of the hazard rates to the specific programmes:

$$
\theta_{p}\left(t_{p} \mid x\left(t_{p}\right), v_{p}\right)=\sum_{j=1}^{J} \theta_{p j}\left(t_{p} \mid x\left(t_{p}\right), v_{p j}\right)
$$


Participation in the $J$ different programmes is denoted by two time-varying $1 \times J$-dimensional vectors of dummy variables, $d_{1}(t)$ and $d_{2}(t)$. The $j$ th element of $d_{1}(t)$ is equal to 1 if the individual is participating in programme $j$ at time $t$, and 0 otherwise; at most, one element of $d_{1}(t)$ is equal to 1 at time $t$. Similarly, the $j$ th element of $d_{2}(t)$ is equal to 1 if the individual participated in programme $j$ before time $t$, but is no longer participating, and 0 otherwise.

The exit rate to employment is given by

$\theta_{u}\left(t_{u} \mid x\left(t_{u}\right), d_{1}\left(t_{u}\right), d_{2}\left(t_{u}\right), v_{u}\right)=\lambda_{u}\left(t_{u}\right) \exp \left(x\left(t_{u}\right) \beta_{u}+d_{1}\left(t_{u}\right) \delta_{1}+d_{2}\left(t_{u}\right) \delta_{2}+v_{u}\right)$

where the baseline hazard $\lambda_{u}\left(t_{u}\right)$ has a form similar to (2), and $\beta, \delta_{1}$ and $\delta_{2}$ are vectors of parameters; $\beta$ is the effect of the control variables, $\delta_{1}$ the lock-in effect, and $\delta_{2}$ the programme effect after completed programme participation. The model takes account of endogeneity of $d_{1}(t)$ and $d_{2}(t)$ through possible correlation between the unobserved variables $v_{u}$ and $v_{p}$.

Let $c$ be a dummy variable equal to 1 if the person exits to employment and 0 otherwise; similarly, let $c_{j}=1$ if the person participates in programme $j$. Then the contribution to the likelihood function of a specific spell, given observed variables, is

$$
\begin{aligned}
L\left(v_{u}, v_{p}\right)= & {\left[\prod_{j=1}^{J} \theta_{p j}\left(t_{p j} \mid x\left(t_{p j}\right), v_{p j}\right)^{1\left\{t_{p j}<t_{u}\right\} c_{j}}\right] \theta_{u}\left(t_{u} \mid x\left(t_{u}\right), d_{1}\left(t_{u}\right), d_{2}\left(t_{u}\right), v_{u}\right)^{c} } \\
& \times \exp \left[-\int_{0}^{t_{p}} \theta_{p}\left(s \mid x(s), v_{p}\right) d s-\int_{0}^{t_{u}} \theta_{u}\left(s \mid x(s), d_{1}(s), d_{2}(s), v_{u}\right) d s\right]
\end{aligned}
$$

The likelihood function is 


$$
L=\iint L\left(v_{u}, v_{p}\right) d F\left(v_{u}, v_{p}\right)
$$

where $F$ is the distribution function of $\left(v_{u}, v_{p}\right)$. To simplify the estimation, we apply a discrete distribution (Heckman and Singer, 1984). Specifically, we assume that $\left(v_{u}, v_{p}\right)$ has a discrete distribution with $2 \times 2$ mass points ${ }^{2}$. This implies that $v_{p}$ follows a binary distribution with mass at 0 and $\left(v_{p 1}, v_{p 2}, \ldots, v_{p J}\right)$, i.e. the unobserved components of the selection into the $J$ different programmes are perfectly correlated, but the correlation between $v_{u}$ and $v_{p}$ is unrestricted.

\section{Marginal effects}

The marginal effects of the control variables on the hazard rate to employment are given by the coefficients $\beta_{u}$ (ignoring the effects via programme participation). Thus, the coefficient of the $h$ 'th explanatory variable, $\beta_{u h}$, is equal to the change in the logarithm of the hazard rate to employment when this variable is changed by 1 unit holding all other variables constant. Similarly, $\delta_{1}$ and $\delta_{2}$ are the marginal lock-in and programme effects, respectively, of participation in labour-market programmes on the hazard rate to employment.

The total effect of participation in a specific programme on the expected duration to employment depends of course on $\delta_{1}$ and $\delta_{2}$, but also on the duration of the programme and, to some extent, on the basic level of the hazard rate to employment (since $\delta_{1}$ and $\delta_{2}$ affect the hazard rate multiplicatively) determined by individual characteristics and starting time of the programme. We calculate the marginal effects of programme participation for a 'reference person' given a range of typical programme starting times and durations. These marginal effects are calculated as the difference in expected mean duration to 
employment with and without programme participation. In these calculations we use restricted mean durations, i.e. expected mean durations up to a predetermined endpoint, $T_{\max }$, which is taken to be four years (because of the rather short observation period). The marginal effects are measured in weeks. Details on the calculation of marginal effects are described in the Appendix.

\section{Data}

We use data from several administrative registers, which are collected and merged by Statistics Denmark. The dataset contains all immigrants in Denmark, and in the analysis we use data for all immigrants meeting the four criteria mentioned in the beginning of Section 2, i.e. they (1) received their residence permit in 2000-2002, (2) were 16-64 years of age at the time of arrival, (3) are from non-EU and non-Nordic countries, (4) are refugees or family reunified. From the administrative data we construct for each immigrant weekly event histories for labour-market states, including Danish language course participation, ALMP participation, and employment. The event histories begin at the date of residence permit and end in the last week of the sample period (or, in case of emigration or death, at the date of this event). In addition, the dataset has information for each individual on a wide range of important demographic and socioeconomic variables which are used as control variables in the analysis.

Data for immigrants’ participation in labour-market programmes are not available before the year 2000. Therefore, the analysis in this paper covers immigrants getting residence permit in the period 2000-2002 (2002 is the last observation year in the dataset).

The dataset contains 21,568 immigrants satisfying the four criteria stated above. Of these, 13,734 received social assistance from the time of residence permit, and 7,834 did not receive any social assistance. In the first group 53\% participated in a labour-market 
programme during the sample period, while in the second group only $7 \%$ participated in ALMPs. The percentages for participation in language courses are $76 \%$ and $56 \%$, respectively. Thus, for the full sample of 21,568 immigrants $36 \%$ are participating in labour-market programmes and 69\% in language courses.

Table 1 shows the distribution of ALMP participants on types of programmes, and the distribution of language course participants on tracks of these courses. In the sample of all immigrants, $18 \%$ of those who participate in language courses are initially placed on track 1 (i.e. they have poor prerequisites for learning Danish, see Section 2), 37\% are on track 2 , and $45 \%$ on track 3 . The sub-sample receiving social assistance initially have on average somewhat poorer prerequisites for learning Danish (the shares on tracks 1 and 2 are higher, and the share on track 3 is correspondingly lower). We have no information on proficiency in Danish for immigrants who have not participated in language courses - 31\% of all immigrants in the sample and $24 \%$ of those who initially received social assistance. This is an important limitation since non-participants may have varying levels of proficiency and different changes in proficiency with exposure to the Danish language.

\section{[TABLE 1 ABOUT HERE]}

Among participants in ALMPs about 20\% participate more than once during the observation period; for about half of these persons, the type of programme in the second programme period is the same as the first programme. However, the figures shown in Table 1 for ALMP participation only concern the first programme for each person. Similarly, the estimated effects of ALMPs which we discuss in the next section are effects of the first ALMP spell (observations for persons participating in programmes more than once are right censored at the duration where the second programme period begins). Among those who participate in 
labour-market programmes, more than one third participate in mixed special programmes, more than one fifth in direct employment programmes in the public sector, and almost one fifth in education and training programmes. Only 2\% of ALMP participants are offered subsidised employment in private sector firms. Descriptive statistics on starting times and duration of labour-market programmes and language courses are given in the Appendix, Tables A2.1 and A2.2.

We include a wide range of controls for individual characteristics in the estimations: the age and number of children, gender, own age, whether the person is married and whether the spouse is an immigrant, country of origin, year of residence permit, basis for residence permit (refugee, family reunified, etc.), health indicators (based on number of visits to the doctor), and whether the immigrant lives in socially deprived housing. We have categorised the variables 'age' and 'number of visits to the doctor' to allow for possible nonlinear effects in a flexible way. Alternative categorisations did not change the main results. We also include variables for local labour-market conditions and immigrant concentration in the municipality of residence. Descriptive statistics for the controls included in the estimations are shown in Appendix 1, Table A1.1.

Unfortunately, we have no information on labour-market experience in the country of origin. Also, we have no information on educational level, except that track placement for language course participants indicates whether the person is illiterate or have a low or high level of schooling; see Section 2.1.

\section{Results}

Table 2 shows estimation results for three different model specifications, each estimated for two different samples: The sample of all immigrants who (1) received their residence permit in 2000-2002, (2) were 16-64 years of age, (3) are from non-EU and non-Nordic countries, (4) 
are refugees or family reunified; and the sub-sample of immigrants who received social assistance from the time when they got their residence permit. In the first model we do not distinguish between different labour-market programmes. In the second model we estimate lock-in and programme effects of each of the six labour-market programmes, and in the third model we allow for further lock-in effects if immigrants participate in labour-market programmes and language courses at the same time. In the third model we also include language course track placement which is an indicator of educational level from the country of origin, see Section 2, and correlated with initial language proficiency and progression in language proficiency.

Table 2 shows estimation results for parameters related to labour-market programmes, language courses and language proficiency only. Estimated coefficients of other explanatory variables are shown in the Appendix, Table A3.1.

[TABLE 2 ABOUT HERE]

\subsection{Participation in language courses and effects of language skills for participants}

Models 1 and 2 include four variables related to language course participation and language skills: (i) a time-varying indicator variable which is equal to 1 if the person participates in language training at the given duration; (ii) a time-varying indicator variable which is equal to 1 if the person has participated in language courses; (iii) a variable for initial proficiency in the Danish language, which is constructed as shown in Figure 1; and (iv) a time-varying variable for progression in language proficiency measured in deviations from the initial level. The sum of the initial proficiency and the progression gives the current proficiency in Danish. These last two variables are explained in Section 2. If a person does not participate in language courses and has not participated (the first two variables are equal to 0), we have no 
information on initial language proficiency (or progression), and the two last variables are set to zero. The coefficient of the first variable corresponds to a lock-in effect which may, however, change (decrease) over time due to progression in Danish language proficiency. When the first variable is zero (the person is not participating in language courses) and the second variable is one (the person has participated), the coefficients of the two last variables and their values correspond to a programme effect of language courses.

In model 3 track placement in language courses (see Section 2) is included, and lock-in and post-programme effects for each of the three tracks are estimated. As explained in Section 2, initial proficiency in the Danish language and progression in proficiency are correlated with track placement, which, however, is also an indicator of level of schooling from the country of origin. Model 3 basically just allows for non-linearity in the impact of language proficiency on job-finding probabilities, when compared to models 1 and 2.

We thus estimate lock-in effects and language-training effects, and both depend on the progression in proficiency in Danish. However, these effects do not have a causal interpretation; see the discussion in Section 3. For immigrants who do participate in language courses, though, it is evident from the estimates in Table 2 that proficiency in Danish is highly significant for the hazard rate to employment: both initial proficiency and progression in proficiency have highly significant positive effects in all models.

\subsection{Effects of participation in labour-market programmes}

In model 1 where we do not distinguish between different labour-market programmes, the lock-in effects of these programmes on the hazard rate to employment are large (numerically) and significant, whereas the (after-)programme effects are insignificant; see Table 2. In model 2 where we estimate separate effects for six different programmes, lock-in effects are present and significant for four of these. The programme effect is only positive and significant for two 
programmes: employment with a wage subsidy, and special employment programmes. Both types of programmes take place in private sector firms, and are not very often offered to newly arrived immigrants; only $1 \%$ and $3 \%$, respectively, participate in these programmes. When the estimation sample is restricted to immigrants who initially receive social assistance benefits, only employment with wage subsidy has a statistically significant programme effect; the point estimate for this programme is larger, whereas the point estimate for special employment programmes is only about one third of the estimate for all immigrants. For one programme (counselling and upgrading) the programme effect is significantly negative (although only marginally so) in the estimation for all immigrants, but insignificant when the sample is restricted to immigrants who initially received social assistance benefits.

In model 3 we include lock-in interaction effects for simultaneous participation in Danish language courses and labour-market programmes. All these interaction effects are negative as expected, and they are statistically significant for three or four of the six programmes (depending on the estimation sample). Correspondingly, the 'marginal' lock-in effects of language courses and labour-market programmes separately are somewhat smaller in model 3 than in model 2. Programme effects in model 3 are similar to the corresponding estimates of model 2: it is the same programmes which have significant effects, and the point estimates are similar. We have also tried to include post-programme interaction effects for simultaneous participation in Danish language courses and labour-market programmes, but they are clearly insignificant indicating that there are no gains from simultaneous participation in language training and ALMPs.

Table 3 shows the marginal effects of participation in labour-market programmes on the restricted mean duration to employment over a four-year period, calculated from a large number of typical programme spells and the estimates of models 2 and 3 of Table 2; see the Appendix. The overall effect for all labour-market programmes taken 
together is insignificant for three of the four estimations, whereas mean duration until regular employment is prolonged by about 5 weeks according to model 3 estimated for all immigrants. However, the effects are very different for different programmes. Thus, for employment with a wage subsidy mean duration is shortened by 14-24 weeks, and for special employment programmes it is shortened by about 9 weeks in the estimations for all immigrants (whereas the effect is insignificant and small for the smaller sample), but mean duration is prolonged by 6-15 weeks for mixed special programmes and counselling and upgrading in the estimates for all immigrants (again, these effects are insignificant for the smaller sample); for the other programmes, the effects are insignificant.

To our knowledge there are no previous studies on effects of ALMPs for newly arrived immigrants. Comparing our results to the broader literature on effects of ALMPs on labour-market outcomes (see the surveys in Stanley et al., 1999; Heckman et al., 1999; Kluve and Schmidt, 2002; Kluve, 2006), the positive effect of employment with a wage subsidy on the hazard rate to regular employment, and the marginally positive or insignificant effect of special employment programmes are consistent with most previous studies. The same is true for our finding of insignificant effects for direct employment programmes and training, and insignificant or marginally negative effects of mixed special programmes. Our finding of a negative effect of counselling and upgrading seems to be in contrast to the literature in that most previous studies find positive effects of counselling, but counselling and upgrading are only significant in the larger of our two samples.

Due to a rather short observation period, our estimates of ALMP effects are short-run estimates where the negative lock-in effects are relatively important. This is also the case for most previous studies in the broader literature on effects of ALMPs. However, it is important to note that some programmes may have positive long-run effects on employment prospects. For instance, this seems to apply for some types of training programmes in 
Germany; see Lechner et al. (2004). Also, programme effects may increase with the (planned) duration of the programme (see Kluve et al., 2007) - a feature which might indicate that estimated programme effects would be larger if the sample period was longer.

\section{Discussion and conclusion}

Using the timing of events duration model and Danish administrative data, this study finds significant and substantial negative lock-in effects of participation in labour-market programmes on the hazard rate to regular employment for newly arrived immigrants. However, the lock-in effects vary by type of programme, and for employment with a wage subsidy there is no indication of lock-in effects: the point estimates indicate that the hazard rate to employment is increased even during programme participation, although these estimates are insignificant. For all types of ALMPs, lock-in effects are larger if the participant attends language courses at the same time.

Programme effects on the hazard rate to employment are significantly positive for private sector subsidised employment programmes, but not for other programmes. For participants in language courses, improvement in language proficiency has substantial positive effects on the hazard rate to employment.

The total effects of participation in ALMPs depend on both lock-in and programme effects. To assess the overall effect of participation we calculate the marginal effects on the mean duration until regular employment over a four-year period, given a range of typical language course and ALMP spells. The effects of ALMPs on mean duration until employment differ between types of programmes. For private sector employment with a wage subsidy the mean duration is shortened by 14-24 weeks, and for special employment programmes it is also shortened (although this effect is insignificant in some estimations), but mean duration is lengthened by mixed special programmes and counselling and upgrading 
(again, these effects are insignificant in some estimations). For the other programmes, the effects are clearly insignificant.

The finding that subsidised private sector employment is by far the most effective type of ALMP is in accordance with the literature on effects of ALMP for unemployed in general (see Section 5.2). It is striking that this type of ALMP is by far the least frequently applied in Denmark; only $2 \%$ of the programmes offered to immigrants are subsidised employment programmes. One way to improve labour-market integration of immigrants may therefore be to increase the number of subsidised jobs offered to newly arrived immigrants. The low number of participants in these programmes is most likely caused by a limited number of participating employers, implying that employers do not find it worthwhile to participate in these programmes.

However, in the present Danish situation with a severe shortage of labour, the benefits to society from increasing labour supply are obvious, hence, the social benefits from the inclusion into the labour force of newly arrived immigrants may exceed the benefits to individual employers, who may worry about costs of training workers who subsequently turn out not to be adequate for the job, or to leave the firm for a different employer. This suggests that there may be a case for further public intervention, possibly by increasing the wage subsidy or increasing contacts between case workers and potential employers.

It is important to note that our sample period is rather short (which is also the case for most previous studies in the broader literature on effects of ALMP), and that some programmes may have positive long-run effects on employment prospects even though shortrun effects may be insignificant or, due to lock-in effects, even negative. For instance, the results in Lechner et al. (2004) indicate that some types of training programmes may have positive long-run effects. 
Even though our results indicate substantially increased lock-in effects when immigrants participate in ALMPs and language courses simultaneously, the positive effects of language proficiency are also very substantial, and gains in language proficiency must be expected to last (and perhaps facilitate further gains in proficiency with exposure to the Danish language), and therefore to have large long-run effects.

Thus, further research on long-run effects of ALMPs and language courses on labour-market outcomes for newly arrived immigrants is needed for more firm policy considerations. 


\section{Appendix}

\section{A1. Descriptive statistics}

Table A1.1 shows descriptive statistics.

[TABLE A1.1 ABOUT HERE]

\section{A2. Marginal effects}

Let $z(t)=\left(x(t), d_{1}(t), d_{2}(t)\right)$ denote the vector of covariates. Let $z^{1}(t)$ denote the covariates when an individual is assigned to a given programme at a given time and with a given duration, and let $z^{0}(t)$ denote covariates when the individual is not assigned to any programme. Then the marginal effect of this programme is defined as the difference in restricted expected durations:

$$
M=E_{T_{\max }}\left[T_{u} \mid z^{1}(t)\right]-E_{T_{\max }}\left[T_{u} \mid z^{0}(t)\right]
$$

where the restricted expected duration is the expected area under the survivor curve up to time $T_{\max }$

$$
E_{T_{\max }}\left[T_{u} \mid z(t)\right]=E\left[\int_{0}^{T_{\max }} S(r) d r\right]
$$

and the survivor function is calculated from the hazard rate: 


$$
S(t)=\exp \left(-\int_{0}^{t} \theta_{u}(s \mid z(s)) d s\right)
$$

We calculate the marginal effects for a 'reference person'. The characteristics chosen for this person (which affect the size of the marginal effects, but not their sign or statistical significance) are given by the reference categories of each set of categorised variables (female, single, no children, 35-44 years of age, from Iraq, family reunified to a non-refugee, not living in a socially deprived neighbourhood) and by average municipal characteristics ( $26.1 \%$ of the jobs in the municipality require high or medium qualifications, the share of immigrants from non-Western countries is $5.9 \%$, and the unemployment rate is $5.4 \%$ ).

Starting time and duration of a given programme vary a lot. Therefore, we calculate ‘the’ marginal effect of a given programme as an average over several typical variants of the programme defined by starting time and duration. Specifically, we use the following simplifying assumptions. Programme spells may have three different starting times and durations defined by the first, second and third quartile in the observed distributions of starting times and durations. Thus, there are nine different types of a given programme, and it is assumed that each type has equal probability (1/9).

For courses in Danish we calculate separate effects for courses at each of the three different tracks, and it is assumed that immigrants do not switch from one track to another and that courses are followed continuously (i.e. they are not interrupted for some time and then resumed). Immigrants at a given track are assumed to have a constant rate of progression in language skills; three different rates of progression are assumed for each track corresponding to the first, second and third quartile in the observed distributions and the three rates are assumed to have the same probability. Finally, assignment to labour-market programmes and language courses are assumed to be independent. When calculating the overall average marginal effect of labour-market programmes, the different programmes are 
weighted according to their frequency in the relevant population; and similarly for language courses.

Table A2.1 shows the characteristics of the synthetic labour-market spells, used to calculate marginal effects, in terms of starting time and duration for each of the two estimation samples (all immigrants, and immigrants initially receiving social assistance, respectively). For instance, in the upper panel of the table (regarding spells for all immigrants), it will be seen that the first, second and third quartile in the distribution of starting times for job training in private firms are 16, 35 and 61 weeks, respectively; and the three quartiles with respect to duration are 14, 26 and 35 weeks, respectively. Similarly, Table A2.2 shows the characteristics of synthetic language courses which also depend on skill progression (measured by the average number of weeks per level of the course). For each of the two estimation samples, our calculations are based on 55 different programme spells ( 9 for each of the 6 types of programmes and 1 for no programme participation) and 82 different language course spells (27 for each of the 3 tracks, and 1 for not attending any language course). Since all possible combinations of programme and language course spells are considered (to take account of interaction effects), there are $4510(55 \times 82)$ combined programme and language course spells for each estimation sample.

[TABLE A2.1 ABOUT HERE]

[TABLE A2.2 ABOUT HERE]

Standard errors of the marginal effects are calculated from simulations of the estimated parameters. Given the estimated parameters and their estimated covariance matrix, we draw 500 random parameter vectors, and calculate the marginal effects for each parameter vector. 
The estimated standard errors of the marginal effects are the standard deviations of the 500 calculated marginal effects.

\section{A3. Estimation results for controls}

Table A3.1 shows the estimated parameters for controls in the hazard rate to employment.

[TABLE A3.1 ABOUT HERE] 


\section{References}

Abbring, J.H. and G.J. van den Berg (2003): The non-parametric identification of treatment effects in duration models. Econometrica 71(5): 1491-1517.

Abbring, J.H.; G.J. van den Berg and J.C. van Ours (2005): The effect of unemployment insurance sanctions on the transition rate from unemployment to employment. Economic Journal 115: 602-630.

Chiswick, B.R. and P.W. Miller (1995): The endogeneity between language and earnings: International analyses. Journal of Labor Economics 13(2): 246-288.

Chiswick, B.R. and P.W. Miller (2003): The complementarity of language and other human capital: immigrant earnings in Canada. Economics of Education Review 22: 469-480.

Crépon, B.; M. Dejemeppe and M. Gurgand (2005): Counselling the unemployed: does it lower unemployment duration and recurrence? IZA Discussion Paper No. 1796, IZA, Bonn.

Heckman, J.J. and B. Singer (1984): A method for minimizing the impact of distributional assumptions in econometric models for duration data. Econometrica 52(2): 271-320.

Heckman, J.J.; R.J Lalonde and J.A. Smith (1999): The Economics and Econometrics of ALMP. Handbook of Labor Economics, 3: 1865-2097. North-Holland, Amsterdam.

Kluve, J. (2006): The effectiveness of European active labour market policy. IZA Discussion Paper No. 2018, IZA, Bonn.

Kluve, J. and C.M. Schmidt (2002): Can training and employment subsidies combat European unemployment? Economic Policy 35: 409-448.

Kluve, J.; H. Schneider, A. Uhlendorff and Z. Zhao (2007): Evaluating continuous training programs using the generalized propensity score. IZA Discussion Paper No. 3255, IZA, Bonn.

Lalive, R.; J.C. van Ours and J. Zweimüller (2005): The effect of benefit sanctions on the duration of unemployment. Journal of the European Economic Association 3(6): 1-32.

Lalive, R.; J.C. van Ours and J. Zweimüller (2008): The impact of active labour market programmes on the duration of unemployment in Switzerland. Economic Journal 118: 235-257.

Lechner, M; R. Miquel and C. Wunch (2004): Long-run effects of public sector sponsored training in West Germany. IZA Discussion Paper No. 1443, IZA, Bonn.

OECD (2005): Trends in International Migration. Annual Report, 2004 Edition.

Pedersen, P.J. (2005) Migration in a Scandinavian welfare state: The recent Danish experience. In Zimmerman, K.F. (ed.) European Migration. Oxford University Press, Oxford.

Richardson, K. and G.J. van den Berg (2001): The effect of vocational employment training on the individual transition rate from unemployment to work. Swedish Economic Policy Review 8(2): $175-213$.

Rosholm, M. and M. Svarer (2008): Estimating the Threat Effect of Active Labour Market Programmes. Scandinavian Journal of Economics (forthcoming).

Stanley, M.; L. Katz and A. Krueger (1999): Impacts of Employment and Training Programmes: The American Experience. Draft, Harvard University.

van den Berg, G.J. (2001): Duration models: specification, identification, and multiple durations. In Heckman, J.J. and E. Leamer (eds.): Handbook of Econometrics, Volume V. NorthHolland, Amsterdam. 
van den Berg, G.J.; B. van der Klaauw and J.C. van Ours (2004): Punitive sanctions and the transition rate from welfare to work. Journal of Labor Economics 22(1): 211-241.

Wadensjö, E. (2001): Immigration, the labour market, and public finances in Denmark. Swedish Economic Policy Review 7(2): 59-84. 
Table 1. Number of immigrants having participated in language courses and labour-market programmes, by track of language courses and type of programmes: All immigrants and the sub-sample receiving social assistance initially (at the time of residence permit)

\begin{tabular}{|c|c|c|c|c|c|c|}
\hline & \multicolumn{3}{|c|}{ All immigrants } & \multicolumn{3}{|c|}{ Receiving social assistance } \\
\hline & Number & $\begin{array}{l}\text { Per cent of } \\
\text { immigrants }\end{array}$ & $\begin{array}{l}\text { Per cent of } \\
\text { participants }\end{array}$ & Number & $\begin{array}{l}\text { Per cent of } \\
\text { immigrants }\end{array}$ & $\begin{array}{l}\text { Per cent of } \\
\text { participants }\end{array}$ \\
\hline \multicolumn{7}{|l|}{$\underline{\text { Language courses }}$} \\
\hline Track 1 & 2655 & 12.3 & 17.9 & 2192 & 16.0 & 20.9 \\
\hline Track 2 & 5449 & 25.3 & 36.7 & 4137 & 30.1 & 39.5 \\
\hline Track 3 & 6733 & 31.2 & 45.4 & 4151 & 30.2 & 39.6 \\
\hline All participants & 14837 & 68.8 & 100.0 & 10480 & 76.3 & 100.0 \\
\hline Non-participants & 6731 & 31.2 & & 3254 & 23.7 & \\
\hline Total & 21568 & 100.0 & & 13734 & 100.0 & \\
\hline \multicolumn{7}{|l|}{$\underline{\text { ALMPS }}$} \\
\hline Employment with wage subsidy & 167 & 0.8 & 2.1 & 155 & 1.1 & 2.1 \\
\hline Direct employment programme & 1656 & 7.7 & 21.2 & 1593 & 11.6 & 22.1 \\
\hline Education and training & 1402 & 6.5 & 17.9 & 1272 & 9.3 & 17.6 \\
\hline Mixed special programmes & 2701 & 12.5 & 34.6 & 2492 & 18.1 & 34.6 \\
\hline Counselling and upgrading & 1182 & 5.5 & 15.1 & 1018 & 7.4 & 14.1 \\
\hline Special employment programme & 709 & 3.3 & 9.1 & 682 & 5.0 & 9.5 \\
\hline All participants & 7817 & 36.2 & 100.0 & 7212 & 52.5 & 100.0 \\
\hline Non-participants & 13751 & 63.8 & & 6522 & 47.5 & \\
\hline Total & 21568 & 100.0 & & 13734 & 100.0 & \\
\hline
\end{tabular}


Table 2. Estimation results: The effects of language courses, language skills and participation in labour-market programmes on the hazard rate to employment for two different samples: all immigrants, and immigrants receiving social assistance benefits

\begin{tabular}{|c|c|c|c|c|c|c|c|c|c|c|c|c|c|c|}
\hline & \multicolumn{7}{|c|}{ All immigrants } & \multicolumn{7}{|c|}{ Immigrants receiving social assistance } \\
\hline & \multicolumn{2}{|c|}{ Model 1} & \multicolumn{3}{|c|}{ Model 2} & \multicolumn{2}{|c|}{ Model 3} & \multicolumn{2}{|c|}{ Model 1} & \multicolumn{3}{|c|}{ Model 2} & \multicolumn{2}{|c|}{ Model 3} \\
\hline & Coeff. & SE & Coeff. & & SE & Coeff. & SE & Coeff. & SE & Coeff. & & SE & Coeff. & SE \\
\hline \multicolumn{15}{|l|}{ Danish language courses and skills: } \\
\hline Participates in language courses & -0.589 & * 0.049 & -0.590 & * & 0.049 & & & -0.756 & * 0.083 & -0.744 & * & 0.085 & . & \\
\hline Has participated in courses & 0.169 & * 0.051 & 0.162 & * & 0.051 & & & 0.232 & * 0.079 & 0.237 & * & 0.081 & . & \\
\hline Initial proficiency in Danish & 0.324 & * 0.032 & 0.301 & * & 0.032 & 0.432 & * 0.046 & 0.453 & * 0.044 & 0.449 & * & 0.045 & 0.495 & * 0.062 \\
\hline Progression in proficiency & 0.318 & * 0.036 & 0.334 & * & 0.037 & 0.364 & * 0.039 & 0.386 & * 0.058 & 0.378 & * & 0.058 & 0.388 & * 0.062 \\
\hline Participates on track 1 of language courses & . & . & . & & . & -0.939 & * 0.093 & . & . & . & & . & -1.351 & * 0.147 \\
\hline Participates on track 2 of language courses & . & . & . & & . & -0.574 & * 0.061 & . & . & . & & . & -0.644 & * 0.099 \\
\hline Participates on track 3 of language courses & . & . & . & & . & -0.550 & * 0.057 & . & . & . & & . & -0.575 & * 0.098 \\
\hline Has participated on track 1 & . & . & . & & . & -0.311 & * 0.095 & . & . & . & & . & -0.578 & * 0.144 \\
\hline Has participated on track 2 & . & . & . & & . & 0.054 & 0.063 & . & . & . & & . & 0.129 & 0.094 \\
\hline Has participated on track 3 & . & . & . & & . & 0.078 & 0.059 & . & . & . & & . & 0.198 & * 0.091 \\
\hline \multicolumn{15}{|l|}{ Active labour-market programmes: } \\
\hline Participates (lock-in effect) & -0.847 & * 0.083 & . & & . & $\cdot$ & & -0.478 & * 0.116 & . & & . & . & \\
\hline Has participated (programme effect) & -0.164 & 0.095 & & & & & & 0.141 & 0.136 & & & & . & \\
\hline \multicolumn{15}{|l|}{ Lock-in effects: } \\
\hline Employment with wage subsidy & . & . & 0.152 & & 0.265 & 0.282 & 0.282 & . & . & 0.442 & & 0.299 & 0.567 & 0.335 \\
\hline Direct employment programme & . & . & -0.529 & * & 0.156 & -0.184 & 0.172 & . & . & -0.727 & * & 0.175 & -0.304 & 0.200 \\
\hline Education and training & . & . & -0.138 & & 0.171 & -0.134 & 0.182 & . & . & -0.362 & * & 0.169 & -0.125 & 0.205 \\
\hline Mixed special programmes & . & . & -0.803 & * & 0.101 & -0.444 & * 0.115 & . & . & -0.270 & & 0.139 & 0.060 & 0.150 \\
\hline Counselling and upgrading & . & . & -1.228 & * & 0.143 & -1.138 & * 0.178 & & . & -0.564 & * & 0.194 & -0.335 & 0.207 \\
\hline Special employment programme & . & . & -0.364 & * & 0.177 & -0.159 & 0.230 & . & . & -0.679 & * & 0.211 & -0.550 & * 0.244 \\
\hline \multicolumn{15}{|l|}{ Programme effects: } \\
\hline Employment with wage subsidy & . & . & 0.875 & * & 0.363 & 0.799 & * 0.360 & & . & 1.372 & * & 0.403 & 1.352 & * 0.416 \\
\hline Direct employment programme & . & . & 0.280 & & 0.185 & 0.159 & 0.182 & - & . & -0.045 & & 0.214 & -0.021 & 0.212 \\
\hline Education and training & . & & 0.243 & & 0.190 & -0.122 & 0.170 & & . & -0.082 & & 0.198 & -0.045 & 0.193 \\
\hline Mixed special programmes & . & & -0.087 & & 0.124 & -0.206 & 0.126 & & . & 0.255 & & 0.160 & 0.237 & 0.161 \\
\hline Counselling and upgrading & . & 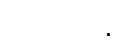 & -0.328 & * & 0.167 & -0.447 & * 0.182 & . & . & 0.290 & & 0.226 & 0.273 & 0.228 \\
\hline Special employment programme &. & & 0.608 & * & 0.178 & 0.597 & * 0.185 & & . & 0.199 & & 0.211 & 0.227 & 0.212 \\
\hline
\end{tabular}




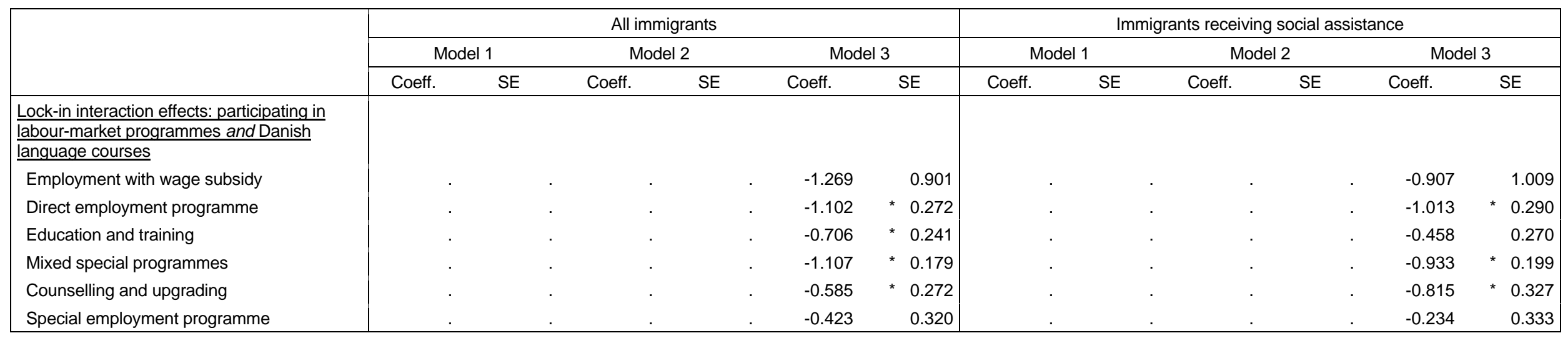

Note: The symbol * indicates significance at the $5 \%$ level. Parameter estimates for other explanatory variables are shown in the Appendix, Table A3.1. Coefficients of the nine duration dependent constant terms of the baseline hazard are not shown. There are observations for 21,568 immigrants in the first three estimations, and 13,734 in the last three.

The coefficient of participating in Danish language courses on track 1 depends on the scaling of the variable for initial proficiency in Danish (see Figure 1); therefore, we have subtracted two times the coefficient of initial proficiency in Danish from the coefficient of track 1.

Two linear restrictions are imposed on the parameters of model 3: The difference between the coefficients of 'Participates on track $j$ of language courses' and 'Has participated on track j' are equal for $j=1,2,3$. 
Table 3. Marginal effects of labour-market programmes: Change in restricted mean duration to employment over a four-year period (measured in weeks)

\begin{tabular}{|c|c|c|c|c|}
\hline & \multicolumn{4}{|c|}{ Sample of immigrants } \\
\hline & \multicolumn{2}{|c|}{ All } & \multicolumn{2}{|c|}{ Receiving social assistance } \\
\hline & Model 2 & Model 3 & Model 2 & Model 3 \\
\hline Labour-market programmes, all & $(1.6)$ & 4.7 & $(-1.0)$ & $(-0.9)$ \\
\hline Employment with wage subsidy & -15.8 & -13.9 & -24.3 & -23.4 \\
\hline Direct employment programme & $(-1.8)$ & $(0.2)$ & $(2.6)$ & $(2.2)$ \\
\hline Education and training & $(-3.8)$ & $(4.5)$ & $(2.1)$ & $(1.6)$ \\
\hline Mixed special programmes & 5.9 & 7.9 & $(-2.7)$ & $(2.2)$ \\
\hline Counselling and upgrading & 11.9 & 14.5 & $(-2.7)$ & $(2.3)$ \\
\hline Special employment programme & -8.7 & -8.9 & $(-0.8)$ & $(1.1)$ \\
\hline
\end{tabular}

Note: The calculation of marginal effects is described in the Appendix. Marginal effects in parentheses are not significant at the $5 \%$ level. 
Table A1.1. Descriptive statistics for controls

\begin{tabular}{|c|c|c|c|c|c|c|c|c|}
\hline & \multicolumn{4}{|c|}{ All immigrants } & \multicolumn{4}{|c|}{$\begin{array}{c}\text { Immigrants } \\
\text { receiving social assistance }\end{array}$} \\
\hline & Mean & SD & Min. & Max. & Mean & SD & Min. & Max. \\
\hline Male without children & 0.3080 & 0.4617 & 0 & 1 & 0.3581 & 0.4795 & 0 & 1 \\
\hline Female * (0-2-year-old children) & 0.0881 & 0.2834 & 0 & 1 & 0.0918 & 0.2888 & 0 & 1 \\
\hline Female * (3-6-year-old children) & 0.0930 & 0.2905 & 0 & 1 & 0.1227 & 0.3281 & 0 & 1 \\
\hline Female * (Number of children) & 0.4880 & 1.1008 & 0 & 10 & 0.6065 & 1.2538 & 0 & 10 \\
\hline Male * (0-2-year-old children) & 0.0513 & 0.2206 & 0 & 1 & 0.0639 & 0.2446 & 0 & 1 \\
\hline Male * (3-6-year-old children) & 0.0556 & 0.2292 & 0 & 1 & 0.0745 & 0.2626 & 0 & 1 \\
\hline Male * (Number of children) & 0.2817 & 0.8763 & 0 & 10 & 0.3587 & 0.9898 & 0 & 10 \\
\hline $16-24$ years of age & 0.2641 & 0.4409 & 0 & 1 & 0.2088 & 0.4065 & 0 & 1 \\
\hline $25-34$ years of age & 0.4388 & 0.4963 & 0 & 1 & 0.4503 & 0.4975 & 0 & 1 \\
\hline $45-64$ years of age & 0.0892 & 0.2850 & 0 & 1 & 0.1060 & 0.3079 & 0 & 1 \\
\hline Married to a non-immigrant & 0.2342 & 0.4235 & 0 & 1 & 0.0955 & 0.2940 & 0 & 1 \\
\hline Married to an immigrant & 0.4554 & 0.4980 & 0 & 1 & 0.5246 & 0.4994 & 0 & 1 \\
\hline Married to a $2^{\text {nd }}$ generation immigrant & 0.0445 & 0.2061 & 0 & 1 & 0.0226 & 0.1485 & 0 & 1 \\
\hline From former Yugoslavia & 0.0818 & 0.2741 & 0 & 1 & 0.0915 & 0.2883 & 0 & 1 \\
\hline From Afghanistan & 0.1183 & 0.3230 & 0 & 1 & 0.1713 & 0.3768 & 0 & 1 \\
\hline From Turkey & 0.0777 & 0.2676 & 0 & 1 & 0.0408 & 0.1979 & 0 & 1 \\
\hline From Somalia & 0.0750 & 0.2634 & 0 & 1 & 0.1081 & 0.3106 & 0 & 1 \\
\hline From Iran & 0.0349 & 0.1836 & 0 & 1 & 0.0402 & 0.1964 & 0 & 1 \\
\hline From other Asian countries & 0.2001 & 0.4001 & 0 & 1 & 0.1240 & 0.3296 & 0 & 1 \\
\hline From other African countries & 0.0735 & 0.2610 & 0 & 1 & 0.0596 & 0.2367 & 0 & 1 \\
\hline From other countries & 0.1414 & 0.3484 & 0 & 1 & 0.0746 & 0.2627 & 0 & 1 \\
\hline Got residence permit in 2000 & 0.3508 & 0.4772 & 0 & 1 & 0.3459 & 0.4757 & 0 & 1 \\
\hline Got residence permit in 2002 & 0.2568 & 0.4369 & 0 & 1 & 0.2291 & 0.4203 & 0 & 1 \\
\hline Refugee & 0.3527 & 0.4778 & 0 & 1 & 0.5226 & 0.4995 & 0 & 1 \\
\hline
\end{tabular}




\begin{tabular}{|c|c|c|c|c|c|c|c|c|}
\hline & \multicolumn{4}{|c|}{ All immigrants } & \multicolumn{4}{|c|}{$\begin{array}{c}\text { Immigrants } \\
\text { receiving social assistance }\end{array}$} \\
\hline & Mean & SD & Min. & Max. & Mean & SD & Min. & Max. \\
\hline Convention refugee & 0.0378 & 0.1908 & 0 & 1 & 0.0545 & 0.2271 & 0 & 1 \\
\hline Family reunified to a refugee & 0.1897 & 0.3921 & 0 & 1 & 0.2557 & 0.4363 & 0 & 1 \\
\hline Share of jobs in municipality requiring high qualifications & 0.2793 & 0.0815 & 0.0963 & 0.4553 & 0.2613 & 0.0784 & 0.0963 & 0.4553 \\
\hline Share of immigrants from non-Western countries in municipality & 0.0719 & 0.0553 & 0.0099 & 0.2431 & 0.0566 & 0.0465 & 0.0099 & 0.2431 \\
\hline Unemployment rate in municipality & 0.0605 & 0.0157 & 0.0286 & 0.1454 & 0.0593 & 0.0163 & 0.0286 & 0.1250 \\
\hline Lives in socially deprived housing & 0.0390 & 0.1936 & 0 & 1 & 0.0359 & 0.1860 & 0 & 1 \\
\hline 1-4 yearly visits to doctors & 0.3882 & 0.4873 & 0 & 1 & 0.3785 & 0.4850 & 0 & 1 \\
\hline $5-9$ yearly visits to doctors & 0.1651 & 0.3713 & 0 & 1 & 0.1793 & 0.3836 & 0 & 1 \\
\hline More than 9 yearly visits to doctors & 0.0851 & 0.2791 & 0 & 1 & 0.1025 & 0.3033 & 0 & 1 \\
\hline
\end{tabular}


Table A2.1 Characteristics of ALMP spells used to calculate marginal effects: Time of programme start and time spent in the programme (in weeks)

\begin{tabular}{|c|c|c|c|c|c|c|c|}
\hline & \multirow{2}{*}{$\begin{array}{c}\text { Weight } \\
\%\end{array}$} & \multicolumn{3}{|c|}{ Start of programme spell } & \multicolumn{3}{|c|}{ Duration of programme } \\
\hline & & Early & Median & Late & Short & Median & Long \\
\hline \multicolumn{8}{|l|}{ Model for all immigrants } \\
\hline Not participating in ALMP & 63.8 & . & . & . & . & . & . \\
\hline Participating, all & 36.2 & 6 & 17 & 40 & 16 & 30 & 52 \\
\hline Employment with wage subsidy & 0.8 & 16 & 35 & 61 & 14 & 26 & 35 \\
\hline Direct employment programme & 7.7 & 9 & 24 & 49 & 17 & 30 & 52 \\
\hline Education and training & 6.5 & 5 & 13 & 32 & 15 & 26 & 48 \\
\hline Mixed special programmes & 12.5 & 7 & 16 & 36 & 18 & 31 & 52 \\
\hline Counselling and upgrading & 5.5 & 4 & 8 & 22 & 13 & 31 & 52 \\
\hline Special employment programme & 3.3 & 13 & 35 & 57 & 13 & 25 & 43 \\
\hline \multicolumn{8}{|c|}{ Model for immigrants receiving social assistance } \\
\hline Not participating in ALMP & 47.5 & . & . & . & . & . & . \\
\hline Participating, all & 52.5 & 6 & 16 & 39 & 17 & 30 & 52 \\
\hline Employment with wage subsidy & 1.1 & 15 & 34 & 61 & 14 & 26 & 35 \\
\hline Direct employment programme & 11.6 & 9 & 22 & 48 & 17 & 30 & 52 \\
\hline Education and training & 9.3 & 4 & 12 & 30 & 17 & 26 & 48 \\
\hline Mixed special programmes & 18.1 & 6 & 15 & 35 & 18 & 31 & 52 \\
\hline Counselling and upgrading & 7.4 & 4 & 8 & 18 & 13 & 34 & 52 \\
\hline Special employment programme & 5.0 & 13 & 34 & 56 & 13 & 25 & 44 \\
\hline
\end{tabular}

Note: Time of programme start and duration are first, second and third quartile in the relevant distribution. 
Table A2.2 Characteristics of Danish language courses (by tracks) used to calculate marginal effects: Time of programme start and time spent in the programme (in weeks), and speed of progression (number of weeks per level of the course)

\begin{tabular}{|c|c|c|c|c|}
\hline \multirow{2}{*}{\multicolumn{2}{|c|}{$\begin{array}{l}\text { Not participating } \\
\text { in language course }\end{array}$}} & \multicolumn{3}{|c|}{ Track of Danish language course } \\
\hline & & Track 1 & Track 2 & Track 3 \\
\hline \multicolumn{5}{|c|}{ Model for all immigrants } \\
\hline Weight (\%) & 31.2 & 14.6 & 25.6 & 28.5 \\
\hline \multicolumn{5}{|c|}{ Starting time of language course (in weeks) } \\
\hline Early & . & 6 & 5 & 5 \\
\hline Median & . & 11 & 9 & 8 \\
\hline Late & . & 19 & 14 & 13 \\
\hline \multicolumn{5}{|c|}{ Duration of language course (in weeks) } \\
\hline Short & . & 32 & 30 & 26 \\
\hline Median & . & 59 & 57 & 51 \\
\hline Long & . & 93 & 90 & 83 \\
\hline \multicolumn{5}{|c|}{ Progression (weeks per level of the course) } \\
\hline Fast & . & 11 & 21 & 11 \\
\hline Median & . & 21 & 29 & 17 \\
\hline Slow & . & 35 & 43 & 26 \\
\hline \multicolumn{5}{|c|}{ Model for immigrants receiving social assistance } \\
\hline Weight (\%) & 23.7 & 18.9 & 30.5 & 26.9 \\
\hline \multicolumn{5}{|c|}{ Starting time of language course (in weeks) } \\
\hline Early & . & 6 & 5 & 5 \\
\hline Median & . & 10 & 8 & 8 \\
\hline Late & . & 18 & 13 & 12 \\
\hline \multicolumn{5}{|c|}{ Duration of language course (in weeks) } \\
\hline Short & . & 35 & 36 & 35 \\
\hline Median & . & 62 & 63 & 60 \\
\hline Long & . & 96 & 96 & 92 \\
\hline \multicolumn{5}{|c|}{ Progression (weeks per level of the course) } \\
\hline Fast & . & 12 & 22 & 13 \\
\hline Median & . & 22 & 31 & 20 \\
\hline Slow & . & 37 & 45 & 31 \\
\hline
\end{tabular}

Note: Starting times, durations and progression are first, second and third quartile, respectively, in the relevant distribution. 
Table A3.1 Estimated parameters for controls in the hazard rate to employment

\begin{tabular}{|c|c|c|c|c|c|c|c|c|c|c|c|c|c|c|c|c|c|c|}
\hline & \multicolumn{18}{|c|}{ Sample of immigrants } \\
\hline & \multicolumn{9}{|c|}{ All } & \multicolumn{9}{|c|}{ Receiving social assistance } \\
\hline & \multicolumn{3}{|c|}{ Model 1} & \multicolumn{3}{|c|}{ Model 2} & \multicolumn{3}{|c|}{ Model 3} & \multicolumn{3}{|c|}{ Model 1} & \multicolumn{3}{|c|}{ Model 2} & \multicolumn{3}{|c|}{ Model 3} \\
\hline & Coeff. & & SE & Coeff. & & SE & Coeff. & & SE & Coeff. & & SE & Coeff. & & SE & Coeff. & & SE \\
\hline Female * $(0-2$ year old children $)$ & -1.153 & * & 0.102 & -1.131 & * & 0.102 & -1.102 & * & 0.101 & -1.003 & * & 0.182 & -1.041 & * & 0.188 & -0.997 & * & 0.187 \\
\hline Female * (3-6 year old children) & -0.856 & A & 0.128 & -0.844 & * & 0.128 & -0.837 & * & 0.126 & -0.619 & * & 0.211 & -0.629 & * & 0.219 & -0.616 & * & 0.218 \\
\hline Female * (Number of children) & 0.152 & * & 0.037 & 0.155 & * & 0.037 & 0.147 & * & 0.036 & 0.025 & & 0.068 & 0.025 & & 0.071 & 0.021 & & 0.070 \\
\hline Male * (3-6 year old children) & -0.335 & * & 0.117 & -0.330 & * & 0.117 & -0.326 & * & 0.117 & 0.022 & & 0.157 & 0.001 & & 0.163 & 0.006 & & 0.161 \\
\hline Male * (Number of children) & 0.056 & & 0.036 & 0.054 & & 0.036 & 0.055 & * & 0.036 & -0.080 & & 0.057 & -0.081 & & 0.059 & -0.080 & & 0.058 \\
\hline $16-24$ years of age & 0.428 & * & 0.060 & 0.421 & * & 0.061 & 0.414 & * & 0.060 & 0.921 & * & 0.100 & 0.919 & * & 0.105 & 0.905 & * & 0.104 \\
\hline $25-34$ years of age & 0.311 & * & 0.055 & 0.310 & * & 0.055 & 0.306 & * & 0.055 & 0.532 & * & 0.087 & 0.547 & * & 0.091 & 0.540 & * & 0.090 \\
\hline $45-64$ years of age & -0.941 & x & 0.102 & -0.926 & * & 0.102 & -0.924 & * & 0.101 & -1.024 & * & 0.178 & -1.068 & * & 0.183 & -1.041 & 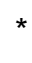 & 0.182 \\
\hline Married to a non-immigrant & 0.165 & * & 0.075 & 0.166 & * & 0.076 & 0.154 & * & 0.075 & 0.639 & * & 0.134 & 0.621 & * & 0.138 & 0.615 & * & 0.137 \\
\hline From Afghanistan & 0.278 & * & 0.100 & 0.259 & * & 0.100 & 0.271 & * & 0.100 & 0.059 & & 0.106 & 0.041 & & 0.113 & 0.041 & & 0.112 \\
\hline From Turkey & 0.923 & * & 0.107 & 0.925 & * & 0.108 & 0.934 & * & 0.107 & 0.815 & * & 0.148 & 0.826 & * & 0.153 & 0.837 & * & 0.152 \\
\hline From Somalia & -0.971 & * & 0.172 & -0.952 & * & 0.172 & -0.935 & * & 0.172 & -0.846 & * & 0.183 & -0.895 & * & 0.190 & -0.866 & * & 0.189 \\
\hline From Iran & -0.073 & & 0.154 & -0.058 & & 0.155 & -0.048 & & 0.154 & 0.231 & & 0.193 & 0.248 & & 0.202 & 0.253 & & 0.200 \\
\hline From other Asian countries & 0.763 & * & 0.095 & 0.772 & * & 0.096 & 0.763 & * & 0.095 & 0.498 & * & 0.116 & 0.514 & * & 0.122 & 0.510 & * & 0.121 \\
\hline From other African countries & 0.891 & * & 0.103 & 0.901 & * & 0.104 & 0.909 & * & 0.103 & 0.704 & * & 0.133 & 0.713 & * & 0.139 & 0.713 & A & 0.138 \\
\hline From other countries & 0.814 & * & 0.100 & 0.830 & * & 0.100 & 0.822 & * & 0.100 & 0.620 & * & 0.131 & 0.681 & * & 0.137 & 0.657 & * & 0.136 \\
\hline Got residence permit in 2000 & 0.053 & & 0.043 & 0.040 & & 0.043 & 0.046 & & 0.042 & 0.014 & & 0.065 & 0.011 & & 0.069 & 0.015 & & 0.068 \\
\hline Got residence permit in 2002 & -0.241 & * & 0.057 & -0.244 & * & 0.057 & -0.242 & * & 0.056 & -0.328 & * & 0.111 & -0.336 & * & 0.114 & -0.332 & * & 0.113 \\
\hline
\end{tabular}




\begin{tabular}{|c|c|c|c|c|c|c|c|c|c|c|c|c|c|c|c|c|c|}
\hline & \multicolumn{17}{|c|}{ Sample of immigrants } \\
\hline & \multicolumn{9}{|c|}{ All } & \multicolumn{8}{|c|}{ Receiving social assistance } \\
\hline & \multicolumn{3}{|c|}{ Model 1} & \multicolumn{3}{|c|}{ Model 2} & \multicolumn{3}{|c|}{ Model 3} & \multicolumn{3}{|c|}{ Model 1} & \multicolumn{3}{|c|}{ Model 2} & \multicolumn{2}{|c|}{ Model 3} \\
\hline & Coeff. & & SE & Coeff. & & SE & Coeff. & & SE & Coeff. & & SE & Coeff. & & SE & Coeff. & SE \\
\hline Convention refugee & -1.974 & * & 0.188 & -2.021 & * & 0.188 & -1.978 & * & 0.18 & -1.389 & * & 0.238 & -1.448 & * & 0.250 & -1.433 & 0.248 \\
\hline Family reunified to a refugee & -1.382 & 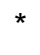 & 0.091 & -1.402 & 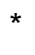 & 0.091 & -1.366 & ^ & 0.09 & -0.936 & * & 0.135 & -0.949 & * & 0.140 & -0.930 & 0.139 \\
\hline $\begin{array}{l}\text { Share of jobs in municipality } \\
\text { requiring high qualifications }\end{array}$ & -0.041 & & 0.035 & -0.043 & & 0.035 & -0.041 & & 0.03 & -0.096 & & 0.055 & -0.039 & & 0.059 & -0.048 & 0.058 \\
\hline Unemployment rate in municipality & -1.097 & * & 0.141 & -1.073 & * & 0.142 & -1.063 & & 0.14 & -0.821 & * & 0.202 & -0.787 & * & 0.216 & -0.797 & 0.213 \\
\hline Lives in socially deprived housing & -0.321 & * & 0.087 & -0.337 & * & 0.087 & -0.329 & 天 & 0.08 & -0.479 & * & 0.135 & -0.470 & * & 0.141 & -0.471 & 0.140 \\
\hline 1-4 yearly visits to doctors & 0.110 & * & 0.041 & 0.108 & 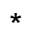 & 0.042 & 0.110 & 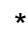 & 0.04 & -0.021 & & 0.065 & -0.009 & & 0.067 & -0.010 & 0.067 \\
\hline 5-9 yearly visits to doctors & -0.092 & & 0.057 & -0.104 & & 0.058 & -0.102 & & 0.05 & -0.388 & * & 0.093 & -0.391 & * & 0.097 & -0.387 & 0.096 \\
\hline More than 9 yearly visits to doctors & -0.379 & * & 0.088 & -0.375 & * & 0.088 & -0.369 & * & 0.08 & -0.531 & * & 0.130 & -0.534 & * & 0.136 & -0.515 & 0.135 \\
\hline
\end{tabular}

Note. Coefficients in parentheses are not significant at the $5 \%$ level. 
Figure 1. Language courses: Tracks, levels and sublevels, and the variable for initial proficiency in the Danish language (initial)

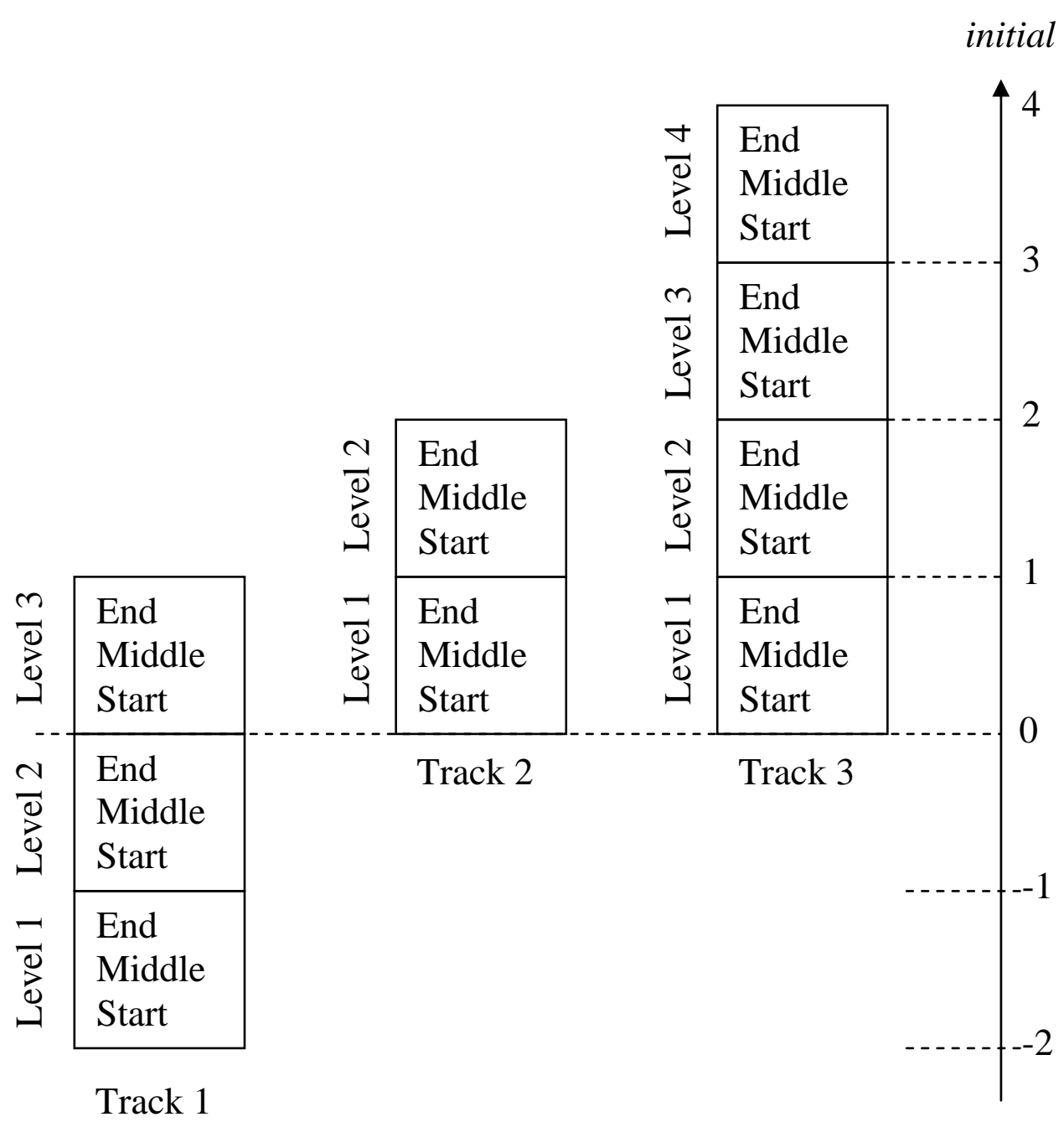




\section{Notes}

1 For instance, an immigrant initially assigned to track 2, level 1, sublevel 'start' is expected to use the same number of lessons to complete level 1 as he will eventually need to complete level 2 . Comparing tracks 2 and 3, an immigrant initially assigned to track 3 (level 1, sublevel 'start') is expected to use only half the number of lessons to complete levels 1 and 2 compared to an immigrant assigned to track 2 (level 1, sublevel 'start'); and the number of lessons needed for the track 3 immigrant to complete level 4 is expected to be about the same as the track 2 immigrant needs to complete level 2. The total number of lessons for immigrants on track 1 is considerably higher than for immigrants on tracks 2 and 3, and the scale for track 1 reflects the fact that the number of lessons needed to complete levels 1, 2 and 3, respectively, are about the same. Having completed level 1 of tracks 2 and 3, or level 3 of track 1, corresponds to proficiency level A2 according to the standard of the Council of Europe (http://www.coe.int/T/DG4/Portfolio/?L=E\&M=/main_pages/levels.html). Having completed level 2 of tracks 2 or 3 corresponds to COE proficiency level B1, whereas completion of levels 3 and 4 of track 3 corresponds to COE levels B2 and C1, respectively.

2 In applications of this method the number of mass points found is typically low; see, e.g., van den Berg (2001). 